\title{
Handedness and midsagittal corpus callosum morphology: a meta-analytic evaluation
}

\author{
René Westerhausen ${ }^{1}\left[\right.$ [ Marietta Papadatou-Pastou ${ }^{2,3}$
}

Received: 29 April 2021 / Accepted: 15 November 2021 / Published online: 1 December 2021

(c) The Author(s) 2021

\begin{abstract}
Following a series of seminal studies in the 1980s, left or mixed hand preference is widely thought to be associated with a larger corpus callosum than right handedness, influencing the interpretation of findings and various theories related to interhemispheric processing, brain lateralisation, and hand preference. Recent reviews, however, find inconsistencies in the literature and cast doubt on the existence of such an association. The present study was conducted to clarify the relationship between hand preference and callosal morphology in a series of meta-analyses. For this purpose, articles were identified via a search in PubMed and Web Of Science databases. Studies reporting findings relating to handedness (assessed as hand preference) and corpus-callosum morphology in healthy participants were considered eligible. On the basis of a total of $k=24$ identified studies and databases, random-effects meta-analyses were conducted considering four different group comparisons: (a) dominantly right- $(\mathrm{dRH})$ and left-hand preference $(\mathrm{dLH}),(\mathrm{b})$ consistent right $(\mathrm{cRH})$ and non-cRH preference, (c) $\mathrm{cRH}$ with mixed-hand preference $(\mathrm{MH})$, and (d) $\mathrm{cRH}$ with consistent left-hand hand preference (cLH). For none of these meta-analyses did we find a significant effect of hand preference, and narrow confidence intervals suggest that the existence of population effects larger than $1 \%$ explained variance could be excluded. For example, considering the comparison of dRH and dLH ( $k=14$ studies; $1910 \mathrm{dRH}$ and $646 \mathrm{dLH}$ participants) the mean effect size was Hedge's $g=0.016$ (95\% confidence interval: -0.12 to 0.15 ; explained variance: $<0.001 \%$ ). Thus, the common practice of assuming an increase in callosal connectivity based on mixed or left hand preference is likely invalid.
\end{abstract}

Keywords Handedness $\cdot$ Corpus callosum $\cdot$ Brain asymmetry $\cdot$ Hand preference

\section{Introduction}

The corpus callosum, formed by a bundle of axons, is essential for the coordination and integration of information processing between and across the two cerebral hemispheres (Gazzaniga 2000). Consequently, it has long been suggested that inter-individual differences in callosal morphology are related to differences in functional hemispheric asymmetries (Galaburda et al. 1990; Ringo et al. 1994; Witelson and Nowakowski 1991). Recent neuroimaging studies in

René Westerhausen

rene.westerhausen@psykologi.uio.no

1 Department of Psychology, University of Oslo, POB 1094 Blindern, 0317 Oslo, Norway

2 Biomedical Research Foundation of the Academy of Athens, Athens, Greece

3 School of Education, National and Kapodistrian University of Athens, Athens, Greece general support this notion as they have shown an association between measures of corpus callosum connectivity and the distribution of neuronal processing between the hemispheres (e.g., Haberling et al. 2011; Josse et al. 2008; Karolis et al. 2019; Labache et al. 2020; Westerhausen et al. 2006).

Hand preference, arguably the most salient functional asymmetry with almost 9 out of 10 individuals being righthanded (Papadatou-Pastou et al. 2020), has also been frequently related to differences in corpus callosum structure and function (for review see, Beaton 1997 and Budisavljevic et al. 2020). These studies can be roughly classified into either of two categories: studies that conceptualise handedness based on the hand preferred for most tasks (direction of hand preference, i.e., left vs. right) or the consistency of hand preference across tasks (consistent vs. inconsistent preference). Although both approaches have been frequently employed in the literature (see Supplementary Tables S1 to S4 for an overview), using the consistency of hand preference has been arguably the most influential and it originates 
in a series of seminal publications by Witelson $(1985,1989)$ and Witelson and Goldsmith (1991). Witelson had measured the area of the midsagittal corpus callosum in the brain specimen of deceased cancer patients of which handedness had been assessed ante mortem using a handedness questionnaire (Annett 1970). Classifying her patients into consistent right-handers (cRH) and inconsistent mixed handers $(\mathrm{MH})$, she found the total corpus callosum to be larger in the $\mathrm{MH}$ group. Witelson interpreted these findings to indicate that a less-lateralized hemispheric organization for hand preference was associated with a stronger or more efficient callosal connectivity than a strongly lateralized organization. Based on this and additional evidence, Witelson derived a theory about the ontogenetic development of functional hemispheric differences (Witelson 1985; Witelson and Nowakowski 1991). That is, she postulated that the degree of functional hemispheric asymmetry (including hand preference) is determined by the magnitude of the loss of callosal axon during late fetal and early postnatal development (LaMantia and Rakic 1990; Innocenti and Price 2005). Strong perinatal axon loss and the resulting limited hemispheric connectivity were thought to promote a strongly lateralised functional brain. A weak axon loss, leaving a comparatively "strong" hemispheric connectivity, in turn, would promote a less pronounced lateralization and hand preference.

Witelson's theory offers a direct neurophysiological explanation for the association of consistency in hand preference (or hemispheric specialization) and corpus callosum morphology. Consequently, studies frequently refer to Witelson's findings when explaining behavioral or cognitive differences between right- and non-right handers that might be linked to the corpus callosum, even without measuring the corpus callosum itself (for some recent examples, see e.g., Jasper et al. 2021, Parker et al. 2017, Roberts et al. 2020, Sala et al. 2017, and Zapała et al. 2020). For example, callosal size differences have been used to explain superior episodic-memory performance in mixed- as compared to consistent (right)-handers (Prichard et al. 2013). However, Witelson's original findings are not necessarily supported by more recent studies and narrative reviews typically summarize the literature as being inconsistent, questioning the existence of a general association (Beaton 1997; Budisavljevic et al. 2020). A quantitative integration of the available studies is, to date, missing.

The aim of the present study was to revisit the question of an association of handedness and corpus callosum morphology using meta-analytic methods. For this purpose, we identified all publications comparing midsagittal corpus callosum morphology in neurologically-healthy participants based on their hand preference. That is, studies were included if they assessed hand preference by self-report (i.e., questionnaire) and used measures of total or subsectional corpus callosum morphology (as volume, area, or thickness) as a dependent variable. As the studies varied in their definition of handedness groups, we could not integrate all data into a single meta-analytic comparison. Rather, we conducted meta-analyses for four different group comparisons: studies that compared participants of (a) dominantly right- $(\mathrm{dRH})$ and dominantly left-hand preference (dLH), (b) consistent right $(\mathrm{cRH})$ with non-cRH preference (NcRH), (c) cRH with mixed-hand preference (MH), and (d) cRH with consistent left-hand preference (cLH). Thus, while metaanalyses (a) and (d) focus on the effect that the direction of hand preference has on the corpus callosum, meta-analyses (b) and (c) also consider the consistency of hand preference. Furthermore, as the interaction of sex and hand preference has received substantial attention in the literature comparing cRH and NcRH samples when explaining total and isthmal corpus-callosum size (Clarke and Zaidel 1994; Habib et al. 1991; Witelson 1989), we conducted a moderator analysis of sex for these comparisons in addition to the overall meta-analysis.

\section{Material and methods}

\section{Study identification}

The study selection was based on a literature search that was conducted on 01. February 2021 on PubMed and Web of Science (Core Collection). The search in PubMed was performed with the search query ("corpus callosum"[All Fields]) AND ("handedness"[All Fields] OR "hand preference" [All Fields]). The search in Web of Science used the search terms (ALL FIELDS: (Corpus callosum) AND ALL FIELDS: (handedness OR hand preference)). Additional studies were identified from the reference list of the selected empirical articles and previous review articles (Beaton 1997; Budisavljevic et al. 2020; Driesen and Raz 1995) and by contacting authors who recently had published corpus callosum data on handedness.

\section{Record screening, article eligibility check, and inclusion}

After removing duplicates, the potential relevance of the study was step-wise evaluated as described in the following. Firstly, title and abstracts were screened to check whether morphological corpus-callosum measures were utilized and that the sample consisted of human participants. If this was the case, the full-text articles were inspected to verify that corpus callosum measures were reported for non-right-handed individuals as well. This step led to the exclusion of studies which had used handedness as an exclusion criterion (typically, excluding nonright handers) or to match participants (without reporting 
the means for handedness groups). In the case of clinical studies, only the data of healthy control groups were considered relevant. In a final evaluation round, it was determined whether sufficient information was available to calculate an effect size measure and include the data in the quantitative meta-analysis. If this was not the case, the corresponding authors were contacted to obtain the relevant data where possible.

The following list provides an overview of all criteria for screening and eligibility assessment:

- Study languages: publications in English, German, and French were considered.

- Species: only data from human (homo sapiens) samples was included.

- Health: only data from neurologically-healthy individuals were considered. Of note, Witelson's seminal work examined patients suffering from peripheral (i.e., not directly affecting the central nervous system) cancer (Witelson 1985, 1989; Witelson and Goldsmith 1991) and was included in the analysis.

- Hand preference had to be assessed using self-report measures, i.e. questionnaires or self-identification. Studies using performance or skill measures for assessment were not included due to sparsity.

- Corpus callosum had to be assessed morphologically regarding its midsagittal shape. Studies reporting raw thickness, area, and volume measures were included.

- Reporting of useable arithmetic data (means and standard deviation or standard error) per group or test statistics (e.g., a $t$-value) for the group comparison.

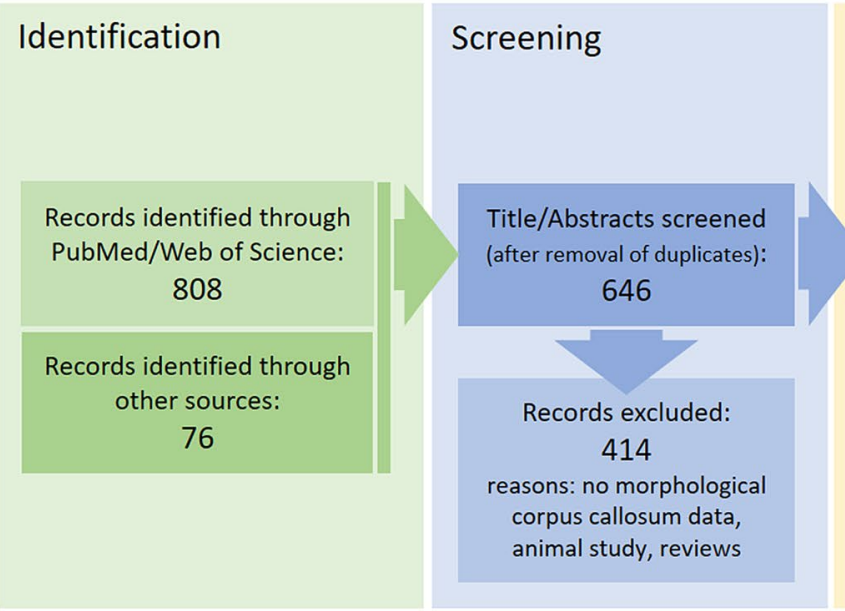

Fig. 1 Overview of study identification, screening, and eligibility assessment. All included studies and datasets are presented in Table 1. All studies that were initially considered eligible but did
An overview of the selection procedure and the number of studies excluded on each step can be found in flow-chart (Fig. 1).

\section{Data extraction}

To assure the independence of observation, the overlap in samples across studies was evaluated and it was made sure that each sample was included only once per meta-analysis. In case of such overlap, only most complete data (e.g., the largest sample) was included. For example, the data reported by Cowell and Gurd (2018) represents a sample extension of the data published earlier (Gurd et al. 2013) thus only data from the larger 2018 sample was included. A second example, Witelson and Goldsmith (1991), reports the results only of an extension of the male sample compared to the Witelson (1989) article, therefore the male data was taken from the later and the female data from the earlier publication.

Regarding hand preference, the method of assessment and potential thresholds for group formation were extracted together with the number of individuals in each group. Of note, as is typical in the handedness literature (Ocklenburg and Güntürkün 2018), the studies included used various criteria to define groups of hand preference. Four main approaches were common in the available literature and accordingly considered in the present set of meta-analyses.

- A classification based on the "handedness direction" so that the overall preference across the activities assessed by a handedness questionnaire determines the classification. Typically, a laterality quotient (LQ) of 0 (equivalent to no hand preference, see e.g., Oldfield (1971)) was used

Eligibility Inclusion

Full-text articles/datasets assessed for eligibility 232

$$
\begin{aligned}
& \text { Articles excluded: } \\
& 208^{*} \\
& \text { reasons: handedness used } \\
& \text { as control variable, sample } \\
& \text { overlap, insufficient data }
\end{aligned}
$$

not provide sufficient information for a statistical inclusion or were redundant (i.e., sample overlap) to other included reports can be found in Supplement Table S5 (with a reason for the exclusion) 
to split the sample into a group of $\mathrm{dRH}$ and $\mathrm{dLH}$ individuals.

- Consistency of hand preference across tasks was considered, by comparing cRH individuals with all other (referred to as NcRH). For this purpose, consistency was defined by the primary studies either by arbitrarily setting a high LQ (e.g., LQ > 80\% in Habib et al. (1991)) as cut-off or by qualitative analyses of the response pattern in the handedness questionnaire. The latter approach follows the suggestion by Witelson (1989), who classified participants as cRH if the answers in Annett's questionnaire (Annett 1970) were "all 'right', or 'right' with some 'either' preferences". All other individuals (i.e., $\mathrm{LQ}<80 \%$; or indicating any 'left' preferences) were consequently defined as not being consistent (NcRH).

- Witelson originally picked this solution, as she was not able to find a sufficiently large sample of consistent lefthanders to form their own group (Witelson 1985). However, later researchers did so, resulting in the possibility of comparing a cRH group with a group of $\mathrm{MH}$ and cLH individuals, as third and fourth comparison, respectively. That is, the NcRH group as defined above, was split into two groups, whereby typically a high negative LQ threshold (e.g., LQ $<-80 \%$ ) was utilized to separate cLH from the $\mathrm{MH}$ group.

Considering the corpus callosum, raw mean and standard deviation of measures of midsagittal callosal morphology (volume, area, thickness) were extracted from the primary articles. The focus on raw measures was necessary as a correction for brain size measures was rarely reported, preventing us from conducting a separate analysis considering brain-size differences. For each study, the method of obtaining the data (i.e., post mortem study or in-vivo MRI; including field strength), the method of callosal segmentation, and the measurement type of the dependent variable (i.e., thickness, area, or volume) was recorded. Where available also measures of corpus callosum subsections were extracted. As the method of dividing the corpus callosum into subsections varies between studies, an attempt was made to apply a common frame of reference across studies. That is, we used the geometrical subdivision schema suggested by Jäncke et al. (1997), which divides the midsagittal corpus callosum surface into four subsections based on the anterior-posterior extend of the structure (see Fig. 2). This schema was considered optimal, as it is sufficiently broad to subsume some of the more fine-grained alternative subdivision schemas, but also includes an isthmus section, which has received particular attention by the literature following Witelson's original findings (see e.g., Denenberg et al. (1991)). A transfer was made by applying the Jäncke et al. (1997) subdivision scheme on the visual representation of the callosal subdivision provided in the literature and determine correspondence

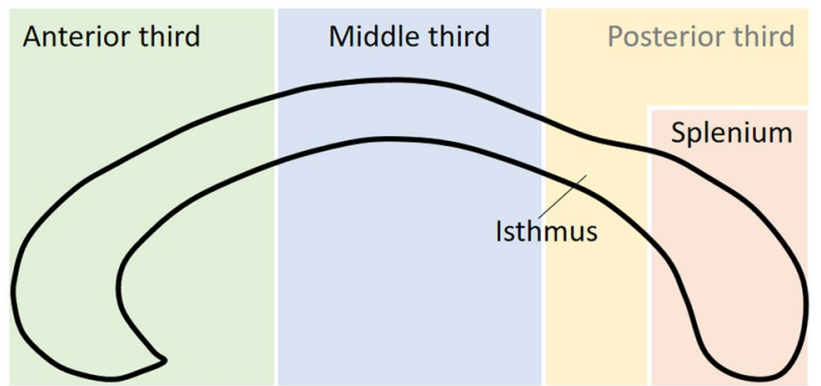

Fig. 2 Illustration of corpus callosum subdivision used in the metaanalyses. The approach followed the straight-line method introduced by Jancke et al. (1997). The outline of the corpus callosum (black line) is divided into thirds relative to its anterior-posterior extend. The posterior third is additionally split into a posterior fifth (i.e., the splenium) and the isthmus

between subdivisions. An illustration of the procedure and the transfer heuristics used can be found in Supplemental material, Fig. S1.

The required corpus callosum data for the meta-analyses was not always readily available in the articles, whereby the following cases were encountered. First, the article did report mean and dispersion of the callosal measures by subgroups (e.g., for female right-handers and male righthanders) but not the entire handedness group. In this case, the data were pooled across the subsamples considering the subsample sizes as weights. Studies where this was the case are indicated in Supplement Tables S1-S4. Second, the article did not report the relevant data, but the author contact was successful. Here the relevant data was either calculated based on the received raw data or the authors were so kind to provide the relevant means and standard deviations. For these cases, a detailed information of the data obtained, the conducted calculations, and results are provided as Supplementary Material Sect. 3. Third, studies did not provide relevant data and authors were non-responsive or no longer traceable. Here, the study was not included in the metaanalyses. A complete list of these studies can be found in Supplement Table S6.

During data extraction, a within study risk-of-bias assessment was done by focussing on the criteria of selective reporting of results. Specifically, it was checked whether the potentially available corpus-callosum data was also reported (see Supplement Table S5). For example, several studies reported to have assessed multiple corpus-callosum subsections but only reported the findings for the significant comparisons (e.g., Hines et al. (1992) and Moffat et al. (1998)). If this was the case, the information was noted and considered when evaluating the outcome of the meta-analyses.

Finally, the sex distribution and age range of each study's sample were recorded in addition to the variables describing the assessment of handedness and corpus callosum 
morphology. An overview of these variables can be found in Table 1 as well as in Supplement Tables S1-S4.

\section{Statistical analysis}

The above-outlined study differences in the handedness classification could not allow for an overall analysis without losing relevant information. We, therefore, decided to conduct a set of four meta-analyses for the following group comparisons: (a) dRH vs. dLH, (b) cRH vs. NcRH, (c) cRH vs. cLH, and (d) cRH vs. MH. Considering (b) we additionally conducted a moderator analysis to explore a suggested interaction of sex and hand preference. The effect size measure Hedges' $g$, reflecting the standardised mean difference of corpus callosum size, was calculated for each study. In all analyses, the pooled effect size was determined assuming a random-effects model. A random-effects model was preferred, as a fixed-effect model was considered inappropriate given the variability in callosal and handedness measures between studies. The between-study variance $\left(\tau^{2}\right)$ was estimated using the DerSimonian-Laird approach and the Hartung-Knapp adjustment was chosen to account for the small number of studies included.

As the number of studies analysing callosal subsections was smaller than the number of studies included in the analysis of the total corpus callosum, we used power analysis to determine the minimal number of studies $\left(k_{\min }\right)$ required to provide a power of at least 0.80 for a population effect size of $d=0.2$ (i.e., a small effect according to Cohen (1992)). For this purpose, we used the average sample size per study and the heterogeneity estimates from the total corpus callosum meta-analyses as best guess values for the subsection analyses. The number of required studies was then determined by iteratively applying the power.analysis script provided with the "dmetar" R package (version 0.0.9; (Harrer et al. 2019) with the above parameters. From this, it was determined that the minimum number of studies for comparison (a) was $k_{\text {min }}=8$, for (b) $k_{\text {min }}=6$, for (c) $k_{\min }=12$, and for (d) $k_{\min }=7$. A meta-analytic integration was only performed when the available number of studies was at least equal to the deter$\operatorname{mined} k_{\min }$.

Visual examination and Egger's regression were used to inspect the funnel plots of each meta-analysis for a potential small study bias. In addition, if one study had a weight in the analysis of $25 \%$ or above, the meta-analysis was repeated without this study to evaluate the stability of the populationeffect size, as a form of sensitivity analysis.

All effect size calculations were done using the "esc" R package (version 0.5.1; (Lüdecke 2018). Meta-analytic procedures were conducted using functions of the libraries "metafor" (version 2.4; Viechtbauer 2020), "meta" (version 4.16-1; Schwarzer 2020), and "dmetar" (version 0.0.9; Harrer et al. 2019) using the $\mathrm{R}$ environment (version 4.0.3). The reporting of the meta-analysis followed the PRISMA checklist (Page et al. 2021) but was not pre-registered.

\section{Results}

\section{Descriptive statistics of included studies}

Data from $k=24$ reports and datasets published between 1985 and 2020 were included in one or several meta-analyses as indicated in Table 1. In 9 (38\%), 7 (29\%), and 5 (21\%) of these studies, hand preference was assessed with versions of the Edinburgh Handedness Inventory (Oldfield 1971), the Annett questionnaire (Annett 1970), or the handedness questionnaires suggested by Bryden (1977), respectively. A total of 23 (96\%) studies provided measures of total corpus callosum size and $16(67 \%)$ studies provided measures for one or more callosal subsections (of note, one study only provided subsection data; see Table 1 for details). The corpus callosum was assessed by post-mortem morphometry in $3(12.5 \%)$ of these reports and using in-vivo magneticresonance imaging in $21(87.5 \%)$ studies. Callosal size was measured as midsagittal area in $21(87.5 \%)$ studies and as volume in $3(12.5 \%)$ studies. Thickness measures were additionally reported in $2(8 \%)$ of the included studies.

\section{Meta-analysis set for the dRH vs. dLH comparison}

Concerning the total corpus callosum area, effect sizes from $k=14$ studies were included in the meta-analysis, which incorporated data from $1910 \mathrm{dRH}$ and $646 \mathrm{dLH}$ participants. Details on the included studies and data extraction can be found the Supplement Table S1. As shown in the forest plot (Fig. 3), the estimated mean effect size $g=0.016$ did not deviate significantly from zero $(t=0.27, p=0.79)$. The $95 \%$ confidence interval (CI 95\%) for $g$ ranged from -0.12 to 0.15 . The between-study variance was $\tau^{2}=0.01$, suggesting a $95 \%$ prediction interval from -0.24 to 0.27 around the mean effect. Neither inspection of the funnel plots (see Supplement Fig. S2) nor the Egger's test of the intercept $(a=-1.35, t=-2.01, p=0.07)$ suggested a small study bias.

Meta-analyses of the subsectional data were not conducted as the number of studies available was below the minimum determined by the a priori power analysis. An overview of the available studies and their effect sizes can be found in Supplement Fig. S4.

\section{Meta-analysis set for the cRH vs. NcRH comparison}

Data from $k=12$ studies (see Supplement Table S2) with a total of $1149 \mathrm{cRH}$ and $1121 \mathrm{NcRH}$ participants were included in the meta-analysis regarding the total corpus 


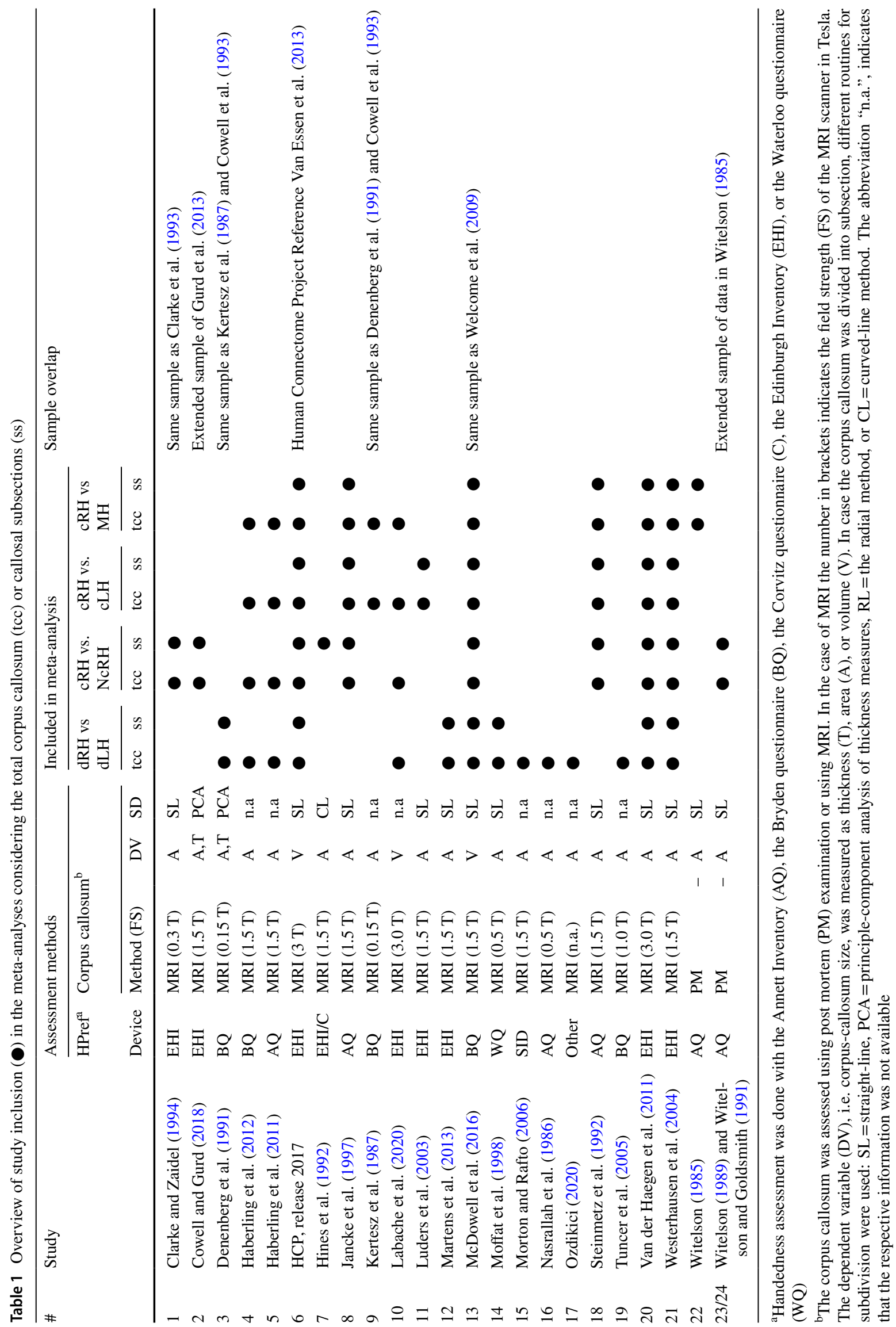


Fig. 3 Forest plot of the metaanalysis of studies comparing dominant right hand $(\mathrm{dRH})$ and dominant left hand $(\mathrm{dLH})$ samples (dependent variable: total corpus callosum size). The total sample size across all $k=14$ studies was $n=1910$ for $\mathrm{dRH}$ and $n=646$ for dLH sample. Negative values indicate the dLH group to have a larger corpus callosum, positive values indicate the $\mathrm{dRH}$ group to have a larger corpus callosum. HCP $2017=$ Human Connectome Project, data release 2017 (see also Van Essen et al. 2013)

\section{Comparison dRH vs. dLH}

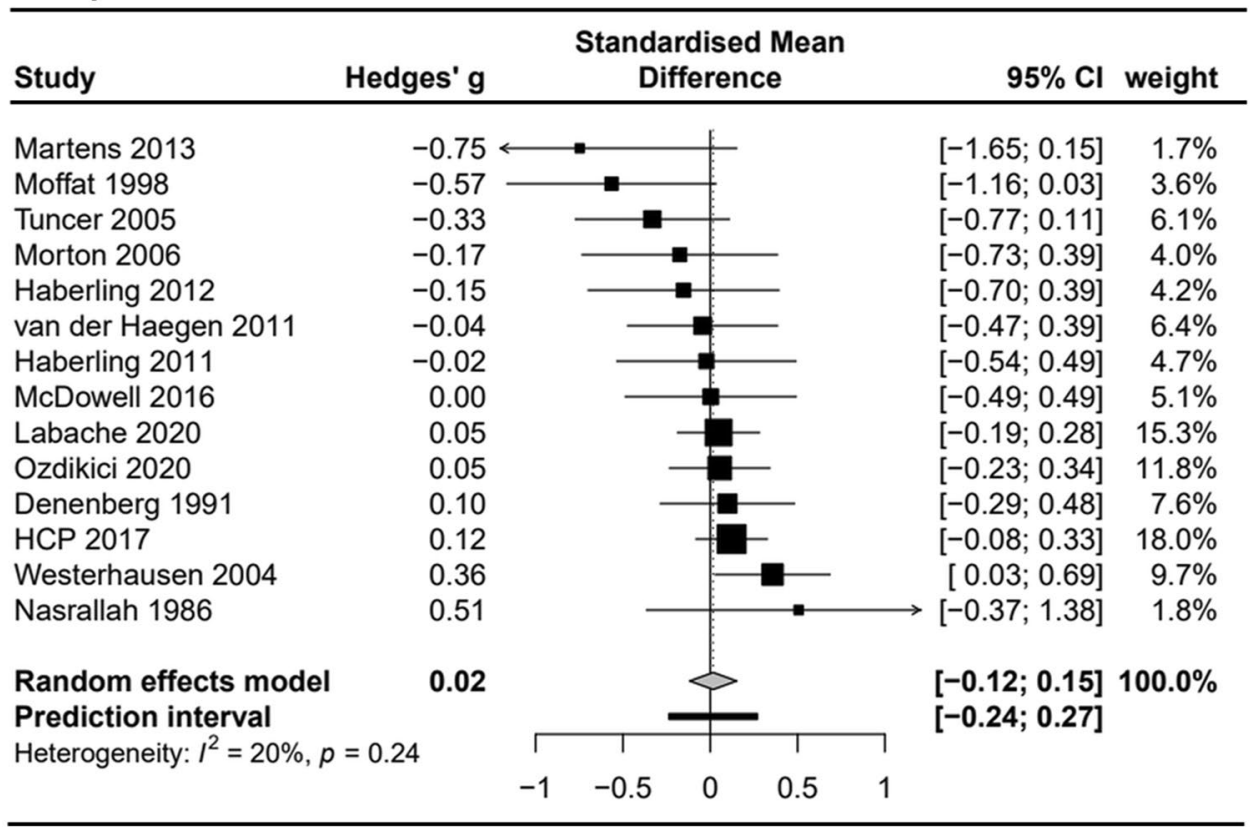

callosum area. The estimated mean effect size $g=-0.02$ (CI 95\% - 0.17; 0.13) did not deviate significantly from zero ( $t=-0.28, p=0.78$; see forest plot Fig. 4). The heterogeneity between studies was $\tau^{2}=0.01$, resulting in a prediction interval from -0.32 to 0.28 . Inspection of the funnel plots (see Supplement Fig. S2) and the Egger's test ( $a=-0.63$, $t=-0.95, p=0.37$ ) did not indicate a small study bias.

Meta-analyses for all four subsections were conducted, but none suggested a significant group effect (see Fig. 5). Concerning the anterior third subregion, the meta-analysis included $k=8$ studies (cRH: $n=946$; NcRH: $n=848$ ) and estimated a mean effect of $g=-0.01$ (CI 95\% -0.19 to $0.16 ; t=-0.19, p=0.85 ; \tau^{2}=0.01$; prediction interval: -0.31 to 0.28$)$. For the middle third, the analysis included $k=9$ studies (cRH: $n=965$; NcRH: $n=881)$ and estimated a mean effect of $g=0.06$ (CI 95\% -0.12 to $0.24 ; t=0.77$, $p=0.46 ; \tau^{2}=0.02$; prediction interval: -0.32 to 0.44$)$. Regarding the isthmus, $k=10$ studies (cRH: $n=985$; NcRH: $n=896$ ) yielded a mean effect of $g=0.01$ (CI 95\% -0.16 to $0.18 ; t=0.12, p=0.91 ; \tau^{2}=0.01$; prediction interval: -0.29
Fig. 4 Forest plot of the metaanalysis of studies comparing consistent right-handers (cRH) and non-cRH ( $\mathrm{NcRH}$ ) (dependent variable: total corpus callosum size). The analysis included $k=12$ studies with a total sample of $n=1149$ for $\mathrm{dRH}$ and $n=1121$ for NcRH. Negative values indicate the $\mathrm{NcRH}$ group to have a larger corpus callosum, positive values indicate the $\mathrm{cRH}$ group to have a larger corpus callosum. HCP $2017=$ Human Connectome Project, data release 2017 (see also Van Essen et al. 2013)

\section{Comparison cRH vs. NcRH}

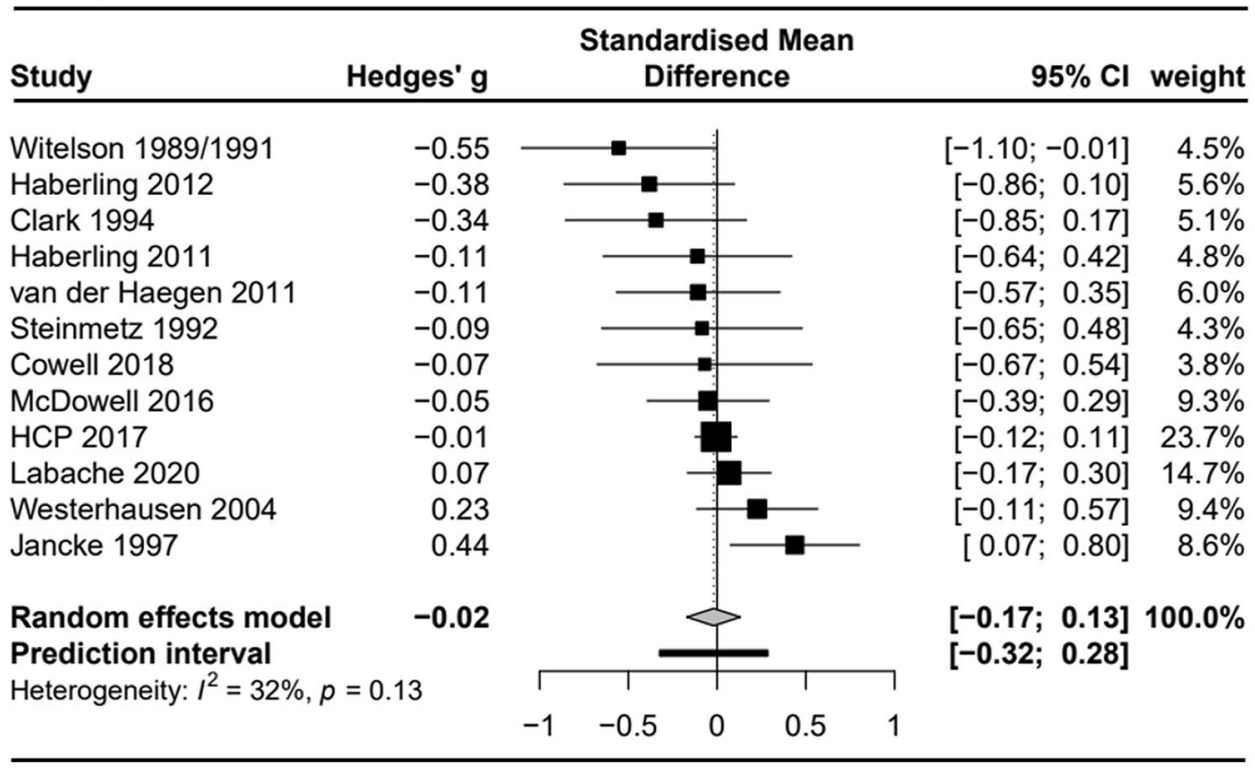




\begin{tabular}{|c|c|c|c|c|c|c|c|c|c|}
\hline Study & $\begin{array}{l}\text { Anterior thir } \\
\text { Hedges' g }\end{array}$ & $\mathrm{se}(\mathrm{g})$ & $\begin{array}{l}\text { Middle third } \\
\text { Hedges' g }\end{array}$ & $\mathrm{se}(\mathrm{g})$ & $\begin{array}{l}\text { Isthmus } \\
\text { Hedges' g }\end{array}$ & $\mathrm{se}(\mathrm{g})$ & $\begin{array}{l}\text { Splenium } \\
\text { Hedges' g }\end{array}$ & $\mathrm{se}(\mathrm{g})$ & \\
\hline Clarke 1994 & -0.42 & 0.26 & -0.08 & 0.26 & -0.16 & 0.26 & -0.30 & 0.26 & \\
\hline Cowell 2018 & -0.18 & 0.31 & 0.09 & 0.31 & 0.00 & 0.31 & -0.07 & 0.31 & \\
\hline НСР 2017 & 0.00 & 0.06 & -0.03 & 0.06 & 0.03 & 0.06 & -0.01 & 0.06 & \\
\hline Hines 1992 & n.a. & n.a. & n.a. & n.a. & -0.38 & 0.39 & n.a. & n.a. & \\
\hline Jäncke 1997 & 0.28 & 0.18 & 0.59 & 0.19 & 0.33 & 0.18 & 0.33 & 0.18 & $\begin{array}{l}\text { Hedges' } \mathrm{g} \\
>0.80\end{array}$ \\
\hline McDowell 2016 & -0.05 & 0.18 & -0.06 & 0.18 & 0.12 & 0.18 & -0.11 & 0.18 & $>0.50$ \\
\hline Steinmetz 1992 & n.a. & n.a. & 0.08 & 0.29 & -0.13 & 0.29 & -0.06 & 0.29 & $>0.20$ \\
\hline vdHaegen 2011 & -0.14 & 0.24 & -0.11 & 0.24 & -0.18 & 0.24 & -0.20 & 0.24 & $\begin{array}{c}>0 \\
0\end{array}$ \\
\hline Westerhausen 2004 & 0.23 & 0.17 & 0.22 & 0.17 & 0.21 & 0.17 & 0.18 & 0.17 & $<0$ \\
\hline Witelson 1989/1991 & -0.40 & 0.30 & -0.25 & 0.30 & -0.61 & 0.28 & -0.28 & 0.30 & $<-0.20$ \\
\hline Average $[\mathrm{Cl}]$ effect & -0.01 & {$[-0.19 ; 0.16]$} & 0.06 & {$[-0.12 ; 0.24]$} & 0.01 & {$[-0.16 ; 0.18]$} & -0.01 & {$[-0.11 ; 0.10]$} & $\begin{array}{l}<-0.50 \\
<-0.80\end{array}$ \\
\hline
\end{tabular}

Fig. 5 Overview of subsection meta-analyses comparing cRH and $\mathrm{NcRH}$ samples. The graph presents the effect size (Hedges' $g$ ) and standard error of the effect size $(\mathrm{se}(g))$ for each study. Negative values indicate the subsection to be larger in the NcRH group, positive values indicate the subsection to be larger in the $\mathrm{cRH}$ group. The provided average effect is estimated using a random-effects model. The

to 0.31$)$. Finally, the mean effect for the splenium region ( $k=9$; cRH: $n=965$; NcRH: $n=881$ ) was $g=-0.01$ (CI $95 \%-0.11$ to $0.10 ; t=-0.14, p=0.89 ; \tau^{2}<0.01$; prediction interval: -0.12 to 0.10 ). All four subsection meta analyses were repeated excluding the HCP data, as this sample contributed with a weight larger $25 \%$. However, the estimated mean estimates were comparable to those above suggesting that the findings are not dominated by the HCP sample (see Supplementary Material Sect. 10 for details).

The additionally conducted subgroup analyses for the variable Sex did neither for the total corpus callosum $(Q=0.09$; $d f=1 ; p=0.77)$ nor for the isthmus subsection find a significant difference $(Q<0.01 ; d f=1 ; p=0.94)$. Regarding the total corpus callosum, the analysis included $k=10$ datasets of a female subgroup, which was characterized by a $g=0.06$ (CI 95\% - 0.05 to $0.16 ; \tau^{2}<0.001$ ). The male subgroup analysis contained $k=9$ datasets, yielding a $g=0.03$ (CI $95 \%-0.19$ to $\left.0.25 ; \tau^{2}=0.02\right)$. Regarding the isthmus, the female subgroup analysis included $k=10$ datasets and suggested a mean effect size of $g=0.04$ (CI 95\% - 0.11 to 0.18 ; $\left.\tau^{2}<0.01\right)$. The male subgroup analysis $(k=8$ datasets $)$ found a $g=0.03$ (CI $95 \%-0.25$ to $\left.0.31 ; \tau^{2}=0.03\right)$. The forest plots of both analyses are presented in Supplement Fig. S3.

\section{Meta-analysis set for the CRH vs. CLH comparison}

The data of $k=11$ studies (see Supplement Table S3) was included in the cRH vs. cLH meta-analysis summarizing the data from a total of $1142 \mathrm{cRH}$ and $306 \mathrm{cLH}$ participants. The group difference in total corpus callosum size was estimated to be $g=0.06$ (CI 95\% - 0.10; 0.23) and did not deviate significantly from zero $(t=0.87, p=0.41)$. As can be seen in the forest plot (Fig. 6), the heterogeneity between studies values in brackets are the $95 \%$ confidence interval. Color coding was based on the Cohen's effect-size heuristics (Cohen 1992) as indicated in the figure legend. Note, for some studies data was not available (n.a.) for some of the subsections. HCP 2017=Human Connectome Project, data release 2017 (see also Van Essen et al. 2013)

was with $\tau^{2}<0.01$ comparatively low, leading to a narrow prediction interval of -0.12 to 0.25 . Neither funnel plots nor Egger's regression ( $a=-1.08, t=-1.01, p=0.34)$ suggested a small study bias. Subsectional meta-analyses were not conducted as the number of studies available was below the minimum determined by the power analysis (see Supplement Fig. S4 for an overview).

\section{Meta-analysis set for the CRH vs. MH comparison}

The meta-analysis contrasting $\mathrm{cRH}$ and $\mathrm{MH}$ groups integrated data from $k=11$ studies (see Supplement Table S4 and forest plot in Fig. 7) with data from a total of $1139 \mathrm{cRH}$ and $810 \mathrm{MH}$ participants. The differences in total corpus callosum size between the groups was estimated to $g=-0.004$ (CI 95\% - 0.20; 0.19) and was not statistically significant $(t=-0.05, p=0.96)$. Between study variance was estimated to $\tau^{2}=0.02$ so that the $95 \%$ prediction interval was -0.40 to 0.40 . No indication for a small study bias was found (Egger's regression: $a=-0.06, t=-0.08, p=0.94$; see funnel plot in Supplement Fig. S2). A subsection analysis was only conducted for the splenium subsection ( $k=7$; cRH: $n=909$; MH: $n=661)$. The mean effect size for the splenium analysis was $g=0.0005$ (CI 95\% - 0.28 to 0.28 ; see also Supplement Fig. S4) and was not significant ( $t=0.00, p=0.996$; $\tau^{2}=0.03$; prediction interval: -0.55 to 0.56$)$.

\section{Discussion}

The present study investigated the presence of differences in corpus-callosum morphology between individuals of different hand preference, using meta-analytic techniques. 
Fig. 6 Forest plot of the metaanalysis of studies comparing consistent right-handers (cRH) and consistent left-handers (cLH) (dependent variable: total corpus callosum size). It included $k=11$ studies with a and $n=306 \mathrm{cLH}$ participants. Negative values indicate the cLH group to have a larger corpus callosum, positive values indicate the $\mathrm{CRH}$ group to have a larger corpus callosum. HCP Project, data release 2017 (see also Van Essen et al. 2013) total sample of $n=1142 \mathrm{cRH}$ $2017=$ Human Connectome

\section{Comparison cRH vs. cLH}

\begin{tabular}{|c|c|c|c|c|c|}
\hline Study & ges' g & & $\begin{array}{r}\text { Standa } \\
\text { Di }\end{array}$ & $95 \% \mathrm{Cl}$ & weight \\
\hline Haberling 2012 & -0.68 & & - & {$[-1.45 ; 0.09]$} & $3.5 \%$ \\
\hline Haberling 2011 & -0.23 & & & {$[-0.89 ; 0.44]$} & $4.7 \%$ \\
\hline Labache 2020 & -0.14 & & & {$[-0.45 ; 0.16]$} & $21.7 \%$ \\
\hline Steinmetz 1992 & -0.10 & & & {$[-0.89 ; 0.70]$} & $3.3 \%$ \\
\hline Luders 2003 & 0.03 & & & {$[-0.48 ; 0.54]$} & $8.0 \%$ \\
\hline McDowell 2016 & 0.04 & & & {$[-0.64 ; 0.72]$} & $4.5 \%$ \\
\hline van der Haegen 2011 & 0.09 & & & {$[-0.41 ; 0.59]$} & $8.2 \%$ \\
\hline Kertesz 1987 & 0.13 & & & {$[-0.35 ; 0.62]$} & $8.7 \%$ \\
\hline Westerhausen 2004 & 0.24 & & & {$[-0.15 ; 0.63]$} & $13.4 \%$ \\
\hline HCP 2017 & 0.31 & & & {$[-0.06 ; 0.69]$} & $14.2 \%$ \\
\hline Jancke 1997 & 0.34 & & & {$[-0.12 ; 0.79]$} & $9.8 \%$ \\
\hline \multirow{4}{*}{$\begin{array}{l}\text { Random effects model } \\
\text { Prediction interval } \\
\text { Heterogeneity: } I^{2}=2 \%, p=0.42\end{array}$} & 0.06 & \multirow{2}{*}{\multicolumn{2}{|c|}{ - }} & \multirow{4}{*}{$\begin{array}{l}{[-0.10 ; 0.23]} \\
{[-0.12 ; 0.25]}\end{array}$} & \multirow{4}{*}{$100.0 \%$} \\
\hline & & & & & \\
\hline & & $\Gamma$ & 1 & & \\
\hline & & -1 & -0.5 & & \\
\hline
\end{tabular}

\section{Comparison cRH vs. $\mathrm{MH}$}

analysis of studies comparing consistent right-handers $(\mathrm{cRH})$ and mixed-handers (MH) (dependent variable: total corpus callosum size). The analysis included $k=11$ studies with a total sample of $n=1139$ cRH and $n=810 \mathrm{MH}$ participants. Negative values indicate the $\mathrm{MH}$ group to have a larger corpus callosum, positive values indicate the $\mathrm{cRH}$ group to have a larger corpus callosum. HCP $2017=$ Human Connectome Project, data release 2017 (see also Van Essen et al. 2013)

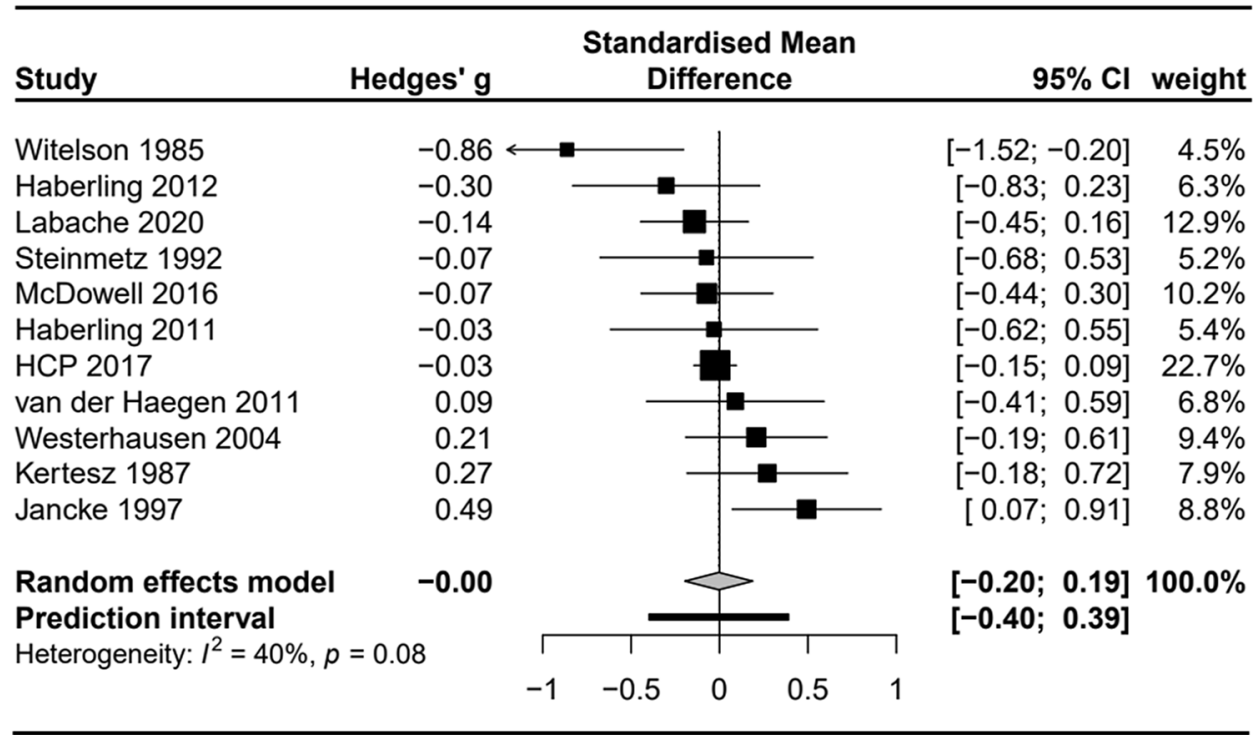

Irrespective of the nature of the compared hand-preference groups, we did not find a significant association of handedness and corpus-callosum morphology, neither for total corpus callosum size, nor for any of its subsections.

The interpretation of these non-significant findings requires first to consider the sensitivity of the conducted analyses. This can be done by referring to the confidence limits of the mean estimates, which provided a range of population effect sizes which cannot be reliably excluded by the available data. Considering the meta-analyses dealing with total corpus callosum size, the largest effect size included in the confidence limits was $g=0.23$ as the upper boundary of the cRH-cLH comparison, which translates to an $r^{2}=0.009$.
Thus, this meta-analysis can exclude population effects which are larger than roughly $1 \%$ of the explained variance. The same applies to the other comparisons, as the confidence limits include even less extreme values. The meta-analyses of the sub-sectional data were comparatively less powerful resulting in wide confidence limits (see e.g., Fig. 5) as a result of the smaller number of studies and reduced overall sample size. Of note, however, also for the isthmus region, which had shown the largest difference between cRH and $\mathrm{NcRH}$ in Witelson's original studies, effects larger $|g|>0.18$ $\left(r^{2}=0.008\right)$ appear unlikely.

Thus, taken together, the present meta-analyses of differences in total corpus callosum size can be taken to exclude 
the existence of population effects larger than $1 \%$ explained variance with reasonable confidence. These effects would be considered "small" following Cohen's effect-size conventions (Cohen 1992). Thus, the population effect sizes that cannot be excluded may be seen as being irrelevant and handedness-related differences in corpus callosum size could be considered negligible for cognition and behavior. On the other hand, as pointed out by Smith (2005), comparatively low amount of explained variances may have a substantial behavioral significance if they accumulate over many events. This may be the case with regard to the corpus callosum, considering its central role in the integration and coordination of information processing between the cerebral hemispheres. Thus, while the present analyses support the exclusion of comparatively small population effect sizes, we are hesitant to attribute functional insignificance to the effect size as it cannot be excluded. Any such conclusion would demand a better understanding of the relationship between variations in size and callosal functioning than currently available. Nevertheless, population-effect sizes of medium to large sizes, as were suggested by Witelson's original work, can be excluded by the present analyses. Thus, we were not able to confirm the original findings neither in terms of the size of the effect nor in terms of statistical significance.

A closer inspection of the forest plots (Figs. 4 and 7) shows that the effect sizes of Witelson's findings fall outside the $95 \%$ confidence interval of the estimated effect size for the respective meta-analysis as well as the prediction interval. The reasons explaining this strong deviation from the effects reported by other studies might be found in several characteristics of Witelson's studies (Witelson 1985, 1989; Witelson and Goldsmith 1991). That is, the data was collected from autopsy specimen (rather than from in-vivo MRI), the study sample was comparatively old, and it was consisting only of (non-CNS) cancer patients. While each of these variables might affect callosal measurements, it appears, however, unlikely that these factors introduce systematic differences between right- and non-right handers. For example, while aging certainly has an effect on corpus callosum morphology (Danielsen et al. 2020; Doraiswamy et al. 1991; Hasan et al. 2008; Salat et al. 1997; Skumlien et al. 2018), the magnitude of aging-related callosal atrophy reduction would have to be more pronounced in NcRH individuals to produce the effect reported by Witelson. Likewise, cancer treatment (e.g., chemotherapy) negatively affects brain white-matter integrity, including the corpus callosum (Deprez et al. 2012), but to the best of our knowledge there is no evidence to suggest that $\mathrm{NcRH}$ are more resilient to these adverse side effects. An alternative explanation might be found when looking at the mean corpus callosum area reported across the three original studies. While the study sample was step-wise expanded by Witelson, the total corpus callosum area reported in particular for the male NcRH subsample decreased from a (comparatively high) value of $800.6 \mathrm{~mm}^{2}$ (sd: $53.9 ; n=5$ ) in 1985 , to $786.3 \mathrm{~mm}^{2}$ (sd: 111.6; $n=6$ ) in 1989 , and to $744.0 \mathrm{~mm}^{2}$ (sd: $109.0 ; n=9$ ) in 1991. At the same time, all other subsample means stayed relatively stable. Therefore, one might speculate that outliers in the initial NcRH sample might have driven Witelson's findings. Thus, Witelson's finding of a larger corpus callosum in NcRH/MH might have been the consequence of a sampling bias.

Another issue that deserves attention is that the present null findings contrast a previous meta-analysis by Driesen and Raz (1995), which found a small effect size of Cohen's $d=-0.13$ (CI 95\% -0.23 to -0.02 ), suggesting a significantly larger corpus callosum area in non-right handers. This meta-analysis included data from seven studies (Clarke and Zaidel 1994; Kertesz et al. 1987; Nasrallah et al. 1986; O'Kusky et al. 1988; Steinmetz et al. 1992; Witelson 1989; Yoshii and Duara 1989), of which the present analyses included five (excluded are the following two studies: (O'Kusky et al. 1988), data only presented for patients with epilepsy, and Yoshii and Duara (1989), published in Japanese). A closer look at the Driesen and Raz (1995) metaanalysis, however, also reveals some differences in the chosen approach. For example, the authors did not account for differences in handedness classification, and ignored, for example, that Nasrallah et al. (1986) compares dRH and dLH participants, while others (Kertesz et al. 1987; Steinmetz et al. 1992; Witelson 1989) compare cRH with NcRH samples. While this lack of specificity is certainly the consequence of the sparsity of studies available in 1995, which prevented a more sophisticated distinction, some inconsistencies in the data extraction remain difficult to explain. For example, in Table 3 (p. 243) Driesen and Raz list an effect size of Cohen's $d=0.10$ for the Steinmetz et al. (1992) study which would indicate larger areas in right-handers. Looking at the data provided in the original study, it rather is the case that the right-handers had the smallest corpus callosum compared to both MH and cLH groups. Furthermore, Driesen and Raz (1995) report an effect size of $d=-0.57$ for a study by O' Kusky et al. (1988). O' Kusky et al. (1988) do not report relevant group differences for the corpus callosum between left- and right-handers. The study only provides a correlation of $r=-0.13$ of handedness LI and callosal area for the studied sample of epileptic patients which might be converted to $d=-0.26$. Consequently, it is not immediately clear where the effect size used in the Driesen and Raz metaanalysis originated.

One limitation of the present meta-analyses is that we were not able to evaluate handedness-related callosal differences controlling for brain-size differences, as the original studies typically did not consider brain size in their analyses or did not report relevant means or test statistics required for a meta-analysis. Thus, it can only be speculated how 
accounting for brain size might affect the handedness comparison. On the one hand, corpus callosum size and brain size are correlated positively (Jancke et al. 1997) so that possible brain-size differences between handedness groups might potentially act as a confounding variable. On the other hand, neither total brain volume nor white or gray matter volume have been found to differ between handedness groups in previous studies (Good et al. 2001; Hervé et al. 2006; Jancke et al. 1997; Luders et al. 2010; Witelson 1989), making a systematic effect less likely. Arguably, most informative for this question are studies reporting analyses of both raw and brain-size corrected data allowing for a direct comparison. Four of these studies did not find any obvious differences for the handedness effect on total corpus callosum size when the correction is applied (Jancke et al. 1997; Mitchell et al. 2003; Nasrallah et al. 1986; Witelson 1989). For example, Witelson (1985) reports a significant larger callosal area in NcRH than cRH both before and after including brain weight into her analysis. Only Hopper et al. (1994) claim in a table legend (i.e., without providing more details) that the body of the corpus callosum was found to be significantly larger in cRH compared to NcRH only after correction for brain size. However, summarizing the above, it appears unlikely that correcting for brain size would substantial change the conclusions compared to the analysis of the raw callosal measures. Nevertheless, it remains for future, large-scale studies to confirm statistically that the effect that hand preferences have on callosal morphology is neither moderated nor confounded by brain size.

A second variable that needs to be considered is the participants' sex, as it may act as both moderator and confounding variable. Sex may be considered a moderator variable, as a series of early studies report an interaction of sex and handedness when predicting total callosal and, in particular, isthmus size (Burke and Yeo 1994; Clarke and Zaidel 1994; Denenberg et al. 1991; Habib et al. 1991; Witelson 1989). That is, a significantly larger isthmus area in NcRH compared to cRH has been found in male but not female participants (Witelson 1989, or Habib et al. 1991, using data corrected for brain size). Burke and Yeo (1994) utilizing the raw $L Q$ score, report a positive correlation of the hand preference and posterior callosal area measures in their male subsample (suggesting that more consistent handedness is associated with a larger structure), while a negative association was reported in the female subsample. However, the present meta-analyses do neither for total nor isthmus area support the notion of an interaction. First, across both metaanalyses neither males nor females showed a significant handedness effect for the cRH-NcRH comparison. Second, the direct comparison of the effect sizes did not yield a significant difference between males and females. Interpreting these findings, one has to keep in mind that the test power of the sex-specific and moderator analyses is reduced compared to omnibus analyses as fewer studies and smaller samples were included. Moreover, the power of moderator variables analysis itself is typically low within meta-analyses. Thus, arguably, more datasets would be beneficial to improve the meta-analyses' sensitivity when it comes to the overall effect estimate, but even more so when it comes to the moderator variables analysis. Nevertheless, the overall pattern of findings provided no evidence for a strong interaction of sex and handedness when explaining corpus callosum morphology.

Meta-analyses and large-scale studies usually find the corpus callosum to be comparable between the sexes or slightly smaller in males once differences in brain size have been accounted for (Driesen and Raz 1995; Eliot et al. 2021; Smith 2005). For the here relevant uncorrected raw measures, however, the male corpus callosum can be expected to be bigger (Bishop and Wahlsten 1997; Luders et al. 2014; Smith 2005). Thus, differences in the proportions of male and female participants in the compared handedness groups might potentially bias the comparison and act as confounding variable. However, a look at the available data (see Tables S1-S4), indicates that the proportions typically were matched well between the compared handedness groups. Nevertheless, to further explore the possibility of a confounding influence of sex, we conducted supplementary meta-regression analyses using the difference in the proportion of females between handedness groups as a covariate. As can be seen in the Supplementary Material Sect. 9, for neither the dRH-dLH nor the cRH-NcRH comparison did we find a significant moderation effect. Thus, while differences in the proportions of males and females might affect the heterogeneity in the data, the differences in proportions are small and do not produce obvious meta-regressive effects, so that we do not believe that these have significantly affected the estimation of the mean effects.

Witelson emphasizes in her studies the relevance of consistency rather than the direction of hand preference (Witelson and Goldsmith 1991). Best comparable with this approach is the meta-analysis comparing cRH and $\mathrm{MH}$ participants, which did not yield a significant effect. However, it also deserves to be mentioned that a small series of studies chose a slightly different approach to the topic by comparing a group of consistent hand preference-containing both cRH and cLH participants-with a non-consistent group (McDowellet al. 2016; Welcome et al. 2009) or which used absolute $L Q$ values in a correlative approach (Habib et al. 1991; Luders et al. 2010). While the group comparisons did not yield any significant association, Habib et al. (1991) found a significant positive correlation, indicating that more consistent individuals had a larger total corpus callosum area (Spearmann $r_{\mathrm{sp}}=0.297, p=0.03 ; n=53$ ). Luders et al. (2010), correlating callosal thickness measures with $|L Q|$, found a cluster of negative associations in the middle third of the corpus callosum $(n=361$, of which 37 were 
$\mathrm{dLH}$ ), thus showing the opposite association to Habib et al. To further explore this association, we conducted a supplementary analysis of the samples of which raw data was available (Labache et al. 2020; McDowell et al. 2016; Van der Haegen et al. 2011; Westerhausen et al. 2004). As can been seen in Supplementary Material Sect. 10, the Spearman correlations of total corpus callosum area and $|L Q|$ for these four samples ranged form $r_{\mathrm{sp}}=-0.15$ to 0.10 , with none of the correlations being significant. Although we refrained from conducting a meta-analysis for these studies, as their number was small, the available evidence does not support the existence of a substantial association of hand preference consistency and callosal measures.

Another consideration is that the present analysis focuses on morphological measures of the corpus callosum and will not be sensitive to differences on the microstructural level. While combined morphological and histological analyses suggest that the midsagittal area is a good predictor of the number of myelinated axons in the corpus callosum (Hou and Pakkenberg 2012; Riise and Pakkenberg 2011), studies comparing the diffusion characteristics of the corpus callosum between handedness groups could provide additional information. Three previous studies indeed suggest stronger anisotropy in the corpus callosum of non-right handers compared to right-handers (McKay et al. 2017; Westerhausen et al. 2004, 2003); all comparing cRH and cLH), potentially suggesting a higher average axon or myelin density in the corpus callosum. Other studies, however, failed to find comparable differences (Haberling et al. 2011; Peled et al. 1998) revealing inconsistency in the literature. Unfortunately, the number of available studies is limited, so that we were not able to conduct a meta-analysis of diffusion data.

Handedness may be assessed via self-report preference questionnaires or via differences in left- and right-hand performance (skill) in manual tasks (Tapley and Bryden 1985). As both do not necessarily correlate highly with each other (Corey et al. 2001), we originally had the intention to perform a separate meta-analysis of studies utilizing measures of hand skill for the assessment of handedness. However, we were only able to identify three such studies so that we refrained from conducting a statistical integration. Kertesz et al. (1987) correlated performance differences between the right and the left hand in a tapping test with total corpus callosum size and did not find a significant association $(r=0.07, n=104)$. Steinmetz et al. (1995) used a paper-and-pencil manual tracing test to classify individuals into dLH $(n=58)$ and dRH individuals $(n=62)$, and did not find a significant difference in corpus-callosum size corrected for forebrain volume. Finally, Preuss et al. (2002), using the same manual tracing test as Steinmetz et al (1995), classified a group of nominal right-handed individuals into $\mathrm{cRH}(n=32)$ and $\mathrm{NcRH}$ sample $(n=14)$, and did not find a significant difference in total callosal size or in any subsection. Thus, while the available evidence does not indicate that corpus-callosum differences can be found when handedness is determined via hand performance measures, the number of studies is small and more evidence is required before a conclusion can be reached.

Finally, the following potential biases from selective reporting and excluded studies deserve consideration when interpreting the findings. Firstly, for most of our meta-analyses concerning the total corpus callosum, a small-study bias is not indicated (through funnel plots and Egger's regression analysis). Nevertheless, some studies, especially when analyzing subsectional data, selectively reported findings based on theoretical considerations (i.e., excluded regions from the analysis as previous studies did not find differences in these regions; e.g., Steinmetz et al. (1992) and Witelson and Goldsmith (1991)) or statistical significance (Hines et al. 1992; Martens et al. 2013; Moffat et al. 1998). In the latter case, this results in underreporting of non-significant, presumably small effect sizes, biasing the meta-analyses to overestimate the population-effect sizes (even when not noticeable in funnel plots). Thus, the effect-size estimates as shown in Fig. 5 need to be interpreted with caution considering this bias. Second, data from several relevant publications had to be excluded as necessary information or data was missing (for details see Supplement Table S5) or not available even after contacting the authors. While the findings of several of these studies were included in the discussion, it has to be emphasized that most of these excluded studies indicate non-significant differences between handedness groups. Thus, it appears likely that the results of the present metaanalyses overestimate the size of the population-effect sizes. However, as none of the meta-analyses yielded significance in the first place, this overestimation of the effect size is unlikely to have affected the conclusions drawn from the present meta-analyses.

In summary, the general interpretation of Witelson's findings (Witelson 1985, 1989; Witelson and Goldsmith 1991) that non-consistent handedness is associated with stronger inter-hemispheric connectivity, is not supported by the present meta-analyses of corpus callosum morphology. About 35 years after the first publication, the original findings have been rendered unreliable by the research they inspired. Thus, any assumption about callosal connections that is made based on hand preference are invalid. However, future large-scale studies are required to allow for a more powerful evaluation of sex differences, brain-size effects, as well as performance measures when studying handedness effects in the corpus callosum.

Supplementary Information The online version contains supplementary material available at https://doi.org/10.1007/s00429-021-02431-4. 
Acknowledgements We would like to thank the authors of the original publications who kindly provided the data and information required for the present meta-analyses. Only thanks to their effort, we were able to conduct meta-analysis of good statistical power.

Author contributions The meta-analysis was conceptualized by both authors, and was conducted (study screening, data extraction, analysis) by RW. The manuscript was written by both authors.

Funding Open access funding provided by University of Oslo (incl Oslo University Hospital). The project was supported by funding from the Department of Psychology, University of Oslo, to RW. The HCP sample data was provided by the Human Connectome Project, WUMinn Consortium (Principal Investigators: David Van Essen and Kamil Ugurbil; 1U54MH091657) funded by the 16 NIH Institutes and Centers that support the NIH Blueprint for Neuroscience Research; and by the McDonnell Center for Systems Neuroscience at Washington University.

\section{Declarations}

Conflict of interest No conflict of interest existing.

Ethics approval Not applicable.

Consent to participate Not applicable.

Consent for publication Not applicable.

Availability of data and material The extracted mean values and standard deviations that served as the basis of the present meta-analyses are available in tabulated form on the accompanying OSF platform (https://osf.io/sw6ev/). The PRISMA checklist is also available on this platform.

Code availability The R scripts used for running the presented analyses are also available on the OSF platform (https://osf.io/sw6ev/), and allow for reproduction of all results.

Open Access This article is licensed under a Creative Commons Attribution 4.0 International License, which permits use, sharing, adaptation, distribution and reproduction in any medium or format, as long as you give appropriate credit to the original author(s) and the source, provide a link to the Creative Commons licence, and indicate if changes were made. The images or other third party material in this article are included in the article's Creative Commons licence, unless indicated otherwise in a credit line to the material. If material is not included in the article's Creative Commons licence and your intended use is not permitted by statutory regulation or exceeds the permitted use, you will need to obtain permission directly from the copyright holder. To view a copy of this licence, visit http://creativecommons.org/licenses/by/4.0/.

\section{References}

\section{The references marked with an asterisk $\left(^{*}\right)$ were included the meta-analyses.}

Annett M (1970) A classification of hand preference by association analysis. Br J Psychol 61(3):303-321
Beaton AA (1997) The relation of planum temporale asymmetry and morphology of the corpus callosum to handedness, gender, and dyslexia: a review of the evidence. Brain Lang 60(2):255-322

Bishop KM, Wahlsten D (1997) Sex differences in the human corpus callosum: myth or reality? Neurosci Biobehav Rev 21(5):581-601

Bryden M (1977) Laterality functional asymmetry in the intact brain, Academic Press, New York

Budisavljevic S, Castiello U, Begliomini C (2020) Handedness and white matter networks. Neuroscientist 27(1):88-103

Burke HL, Yeo RA (1994) Systematic variations in callosal morphology: the effects of age, gender, hand preference, and anatomic asymmetry. Neuropsychology 8(4):563-571

*Clarke JM, Zaidel E (1994) Anatomical-behavioral relationships: corpus callosum morphometry and hemispheric specialization. Behav Brain Res 64(1-2):185-202. https://doi.org/10.1016/01664328(94)90131-7

Clarke JM, Lufkin RB, Zaidel F (1993) Corpus-callosum morphometry and dichotic-listening performance-individual diiderences in functional interhemispheric inhibition. Neuropsychologia 31(6):547-557. https://doi.org/10.1016/0028-3932(93)90051-z

Cohen J (1992) A power primer. Psychol Bull 112(1):155

Corey DM, Hurley MM, Foundas AL (2001) Right and left handedness defined: a multivariate approach using hand preference and hand performance measures. Cogn Behav Neurol 14(3):144-152

*Cowell PE, Gurd J (2018) Handedness and the corpus callosum: a review and further analyses of discordant twins. Neuroscience 388:57-68. https://doi.org/10.1016/j.neuroscience.2018.06.017

Cowell PE, Kertesz A, Denenberg VH (1993) Multiple dimensions of handedness and the human corpus callosum. Neurology 43(11):2353-2357. https://doi.org/10.1212/wnl.43.11.2353

Danielsen VM, Vidal-Piñeiro D, Mowinckel AM, Sederevicius D, Fjell AM, Walhovd KB, Westerhausen R (2020) Lifespan trajectories of relative corpus callosum thickness: regional differences and cognitive relevance. Cortex 130:127-141

*Denenberg VH, Kertesz A, Cowell PE (1991) A factor analysis of the human's corpus callosum. Brain Res 548(1-2):126-132. https:// doi.org/10.1016/0006-8993(91)91113-f

Deprez S, Amant F, Smeets A, Peeters R, Leemans A, Van Hecke W et al (2012) Longitudinal assessment of chemotherapy-induced structural changes in cerebral white matter and its correlation with impaired cognitive functioning. J Clin Oncol 30(3):274-281

Doraiswamy PM, Figiel GS, Husain MM, McDonald WM, Shah SA, Boyko OB, Krishnan KR (1991) Aging of the human corpus callosum: magnetic resonance imaging in normal volunteers. J Neuropsychiatry Clin Neurosci 3(4):392-397. https://doi.org/10. 1176/jnp.3.4.392

Driesen NR, Raz N (1995) The influence of sex, age, and handedness on corpus callosum morphology: a meta-analysis. Psychobiology 23(3):240-247

Eliot L, Ahmed A, Khan H, Patel J (2021) Dump the "dimorphism": comprehensive synthesis of human brain studies reveals few male-female differences beyond size. Neurosci Biobehav Rev 125:667-697

Galaburda AM, Rosen GD, Sherman GF (1990) Individual variability in cortical organization: its relationship to brain laterality and implications to function. Neuropsychologia 28(6):529-546

Gazzaniga MS (2000) Cerebral specialization and interhemispheric communication: does the corpus callosum enable the human condition? Brain 123(Pt 7):1293-1326

Good CD, Johnsrude I, Ashburner J, Henson RN, Friston KJ, Frackowiak RS (2001) Cerebral asymmetry and the effects of sex and handedness on brain structure: a voxel-based morphometric analysis of 465 normal adult human brains. Neuroimage 14(3):685-700

Gurd JM, Cowell PE, Lux S, Rezai R, Cherkas L, Ebers GC (2013) fMRI and corpus callosum relationships in monozygotic twins 
discordant for handedness. Brain Struct Funct 218(2):491-509. https://doi.org/10.1007/s00429-012-0410-9

*Haberling IS, Badzakova-Trajkov G, Corballis MC (2011) Callosal tracts and patterns of hemispheric dominance: a combined fMRI and DTI study. Neuroimage 54(2):779-786. https://doi.org/10. 1016/j.neuroimage.2010.09.072

*Haberling IS, Badzakova-Trajkov G, Corballis MC (2012) The corpus callosum in monozygotic twins concordant and discordant for handedness and language dominance. J Cogn Neurosci 24(10):1971-1982

*Habib M, Gayraud D, Oliva A, Regis J, Salamon G, Khalil R (1991) Effects of handedness and sex on the morphology of the corpus callosum: a study with brain magnetic resonance imaging. Brain Cogn 16(1):41-61

Harrer M, Cuijpers P, Furukawa T, Ebert DD (2019) dmetar: Companion R package for the guide 'Doing Meta-Analysis in R'. http:// dmetar.protectlab.org/

Hasan KM, Ewing-Cobbs L, Kramer LA, Fletcher JM, Narayana PA (2008) Diffusion tensor quantification of the macrostructure and microstructure of human midsagittal corpus callosum across the lifespan. NMR Biomed 21(10):1094-1101. https://doi.org/10. 1002/nbm.1286

Hervé P-Y, Crivello F, Perchey G, Mazoyer B, Tzourio-Mazoyer N (2006) Handedness and cerebral anatomical asymmetries in young adult males. Neuroimage 29(4):1066-1079

*Hines M, Chiu L, McAdams LA, Bentler PM, Lipcamon J (1992) Cognition and the corpus callosum: verbal fluency, visuospatial ability, and language lateralization related to midsagittal surface areas of callosal subregions. Behav Neurosci 106(1):3

Hopper KD, Patel S, Cann TS, Wilcox T, Schaeffer JM (1994) The relationship of age, gender, handedness, and sidedness to the size of the corpus callosum. Acad Radiol 1(3):243-248. https:// doi.org/10.1016/s1076-6332(05)80723-8

Hou J, Pakkenberg B (2012) Age-related degeneration of corpus callosum in the $90+$ years measured with stereology. Neurobiol Aging. https://doi.org/10.1016/j.neurobiolaging.2011.10.017

Innocenti GM, Price DJ (2005) Exuberance in the development of cortical networks. Nat Rev Neurosci 6(12):955-965. https://doi. org/10.1038/nrn1790

*Jancke L, Staiger JF, Schlaug G, Huang YX, Steinmetz H (1997) The relationship between corpus callosum size and forebrain volume. Cereb Cortex 7(1):48-56. https://doi.org/10.1093/cercor/7.1.48

Jasper JD, Christman SD, Clarkson E (2021) Predicting interactions in handedness research: the role of integrated versus independent dual-processes. Laterality. https://doi.org/10.1080/13576 50X.2021.1879110

Josse G, Seghier ML, Kherif F, Price CJ (2008) Explaining function with anatomy: language lateralization and corpus callosum size. J Neurosci 28(52):14132-14139. https://doi.org/10.1523/jneur osci.4383-08.2008

Karolis VR, Corbetta M, De Schotten MT (2019) The architecture of functional lateralisation and its relationship to callosal connectivity in the human brain. Nat Commun 10(1):1-9

*Kertesz A, Polk M, Howell J, Black SE (1987) Cerebral dominance, sex, and callosal size in MRI. Neurology 37(8):1385-1388. https://doi.org/10.1212/wnl.37.8.1385

*Labache L, Mazoyer B, Joliot M, Crivello F, Hesling I, TzourioMazoyer N (2020) Typical and atypical language brain organization based on intrinsic connectivity and multitask functional asymmetries. Elife. https://doi.org/10.7554/eLife.58722

LaMantia AS, Rakic P (1990) Axon overproduction and elimination in the corpus callosum of the developing rhesus monkey. $\mathrm{J}$ Neurosci 10(7):2156-2175

Lüdecke D (2018) esc: Effect size computation for meta analysis. https://CRAN.R-project.org/package=esc
*Luders E, Rex DE, Narr KL, Woods RP, Jancke L, Thompson PM, Toga AW (2003) Relationships between sulcal asymmetries and corpus callosum size: gender and handedness effects. Cereb Cortex 13(10):1084-1093. https://doi.org/10.1093/cercor/13. 10.1084

Luders E, Cherbuin N, Thompson PM, Gutman B, Anstey KJ, Sachdev P, Toga AW (2010) When more is less: associations between corpus callosum size and handedness lateralization. Neuroimage 52(1):43-49. https://doi.org/10.1016/j.neuroimage.2010.04.016

Luders E, Toga AW, Thompson PM (2014) Why size matters: differences in brain volume account for apparent sex differences in callosal anatomy: the sexual dimorphism of the corpus callosum. Neuroimage 84:820-824. https://doi.org/10.1016/j.neuroimage. 2013.09.040

*Martens MA, Wilson SJ, Chen J, Wood AG, Reutens DC (2013) Handedness and corpus callosal morphology in Williams syndrome. Dev Psychopathol 25(1):253-260. https://doi.org/10.1017/ s0954579412001009

*McDowell A, Felton A, Vazquez D, Chiarello C (2016) Neurostructural correlates of consistent and weak handedness. Laterality 21(4-6):348-370. https://doi.org/10.1080/1357650x.2015.10969 39

McKay NS, Iwabuchi SJ, Häberling IS, Corballis MC, Kirk IJ (2017) Atypical white matter microstructure in left-handed individuals. Laterality Asymmetries Body Brain Cogn 22(3):257-267

Mitchell TN, Free SL, Merschhemke M, Lemieux L, Sisodiya SM, Shorvon SD (2003) Reliable callosal measurement: population normative data confirm sex-related differences. Am J Neuroradiol 24(3):410-418

*Moffat SD, Hampson E, Lee DH (1998) Morphology of the planum temporale and corpus callosum in left handers with evidence of left and right hemisphere speech representation. Brain 121:23692379. https://doi.org/10.1093/brain/121.12.2369

*Morton BE, Rafto SE (2006) Corpus callosum size is linked to dichotic deafness and hemisphericity, not sex or handedness. Brain Cogn 62(1):1-8. https://doi.org/10.1016/j.bandc.2006.03. 001

*Nasrallah HA, Andreasen NC, Coffman JA, Olson SC, Dunn VD, Ehrhardt JC, Chapman SM (1986) A controlled magnetic resonance imaging study of corpus callosum thickness in schizophrenia. Biol Psychiatry 21(3):274-282. https://doi.org/10.1016/ 0006-3223(86)90048-x

Ocklenburg S, Güntürkün O (2018) The lateralized brain: the neuroscience and evolution of hemispheric asymmetries. Academic Press, London

O’Kusky J, Strauss E, Kosaka B, Wada J, Li D, Druhan M, Petrie J (1988) The corpus callosum is larger with right-hemisphere cerebral speech dominance. Ann Neurol 24(3):379-383

Oldfield RC (1971) The assessment and analysis of handedness: the Edinburgh inventory. Neuropsychologia 9(1):97-113

*Ozdikici M (2020) Measurment of midsagittal corpus callosum area with the modified Cavalieri method in healthy right- and lefthanded Turkish adults. Malang Neurol J 6(1):24-27

Page MJ, Moher D, Bossuyt PM, Boutron I, Hoffmann TC, Mulrow CD, Brennan SE (2021) PRISMA 2020 explanation and elaboration: updated guidance and exemplars for reporting systematic reviews. BMJ 372:n160

Papadatou-Pastou M, Ntolka E, Schmitz J, Martin M, Munafò MR, Ocklenburg S, Paracchini S (2020) Human handedness: a metaanalysis. Psychol Bull 146(6):481-524

Parker A, Parkin A, Dagnall N (2017) Effects of handedness and saccadic bilateral eye movements on the specificity of past autobiographical memory and episodic future thinking. Brain Cogn 114:40-51 
Peled S, Gudbjartsson H, Westin C-F, Kikinis R, Jolesz FA (1998) Magnetic resonance imaging shows orientation and asymmetry of white matter fiber tracts. Brain Res 780(1):27-33

Preuss UW, Meisenzahl EM, Frodl T, Zetzsche T, Holder J, Leinsinger $\mathrm{G}$ et al (2002) Handedness and corpus callosum morphology. Psychiatry Res 116(1-2):33-42. https://doi.org/10.1016/s09254927(02)00064-1

Prichard E, Propper RE, Christman SD (2013) Degree of handedness, but not direction, is a systematic predictor of cognitive performance. Front Psychol 4:9

Reinarz SJ, Coffman CE, Smoker WR, Godersky JC (1988) MR imaging of the corpus callosum: normal and pathologic findings and correlation with CT. Am J Roentgenol 151(4):791-798

Riise J, Pakkenberg B (2011) Stereological estimation of the total number of myelinated callosal fibers in human subjects. J Anat 218(3):277-284

Ringo JL, Doty RW, Demeter S, Simard PY (1994) Time is of the essence: a conjecture that hemispheric specialization arises from interhemispheric conduction delay. Cereb Cortex 4(4):331-343

Roberts BR, Fernandes MA, MacLeod CM (2020) Re-evaluating whether bilateral eye movements influence memory retrieval. PLoS ONE 15(1): $\mathrm{e} 0227790$

Sala G, Signorelli M, Barsuola G, Bolognese M, Gobet F (2017) The relationship between handedness and mathematics is non-linear and is moderated by gender, age, and type of task. Front Psychol 8:948

Salat D, Ward A, Kaye JA, Janowsky JS (1997) Sex differences in the corpus callosum with aging. Neurobiol Aging 18(2):191-197. https://doi.org/10.1016/s0197-4580(97)00014-6

Schwarzer G (2020). meta: General package for meta-analysis. https:// CRAN.R-project.org/package $=$ meta

Skumlien M, Sederevicius D, Fjell AM, Walhovd KB, Westerhausen R (2018) Parallel but independent reduction of emotional awareness and corpus callosum connectivity in older age. PLoS ONE 13(12):e0209915

Smith RJ (2005) Relative size versus controlling for size. Curr Anthropol 46(2):249-273

*Steinmetz H, Jäncke L, Kleinschmidt A, Schlaug G, Volkmann J, Huang Y (1992) Sex but no hand difference in the isthmus of the corpus callosum. Neurology 42(4):749-752. https://doi.org/10. 1212/wnl.42.4.749

Steinmetz H, Staiger JF, Schlaug G, Huang Y, Jäncke L (1995) Corpus callosum and brain volume in women and men. NeuroReport 6(7):1002-1004. https://doi.org/10.1097/00001756-19950 5090-00013

Tapley S, Bryden M (1985) A group test for the assessment of performance between the hands. Neuropsychologia 23(2):215-221

*Tuncer MC, Hatipoglu ES, Ozates M (2005) Sexual dimorphism and handedness in the human corpus callosum based on magnetic resonance imaging. Surg Radiol Anat 27(3):254-259. https://doi. org/10.1007/s00276-004-0308-1

*Van der Haegen L, Cai Q, Seurinck R, Brysbaert M (2011) Further fMRI validation of the visual half field technique as an indicator of language laterality: a large-group analysis. Neuropsychologia 49(10):2879-2888

*Van Essen DC, Smith SM, Barch DM, Behrens TE, Yacoub E, Ugurbil K, HCP-Consortium (2013) The WU-Minn human connectome project: an overview. Neuroimage 80:62-79

Viechtbauer W (2020) metafor: Meta-analysis package for R. https:// CRAN.R-project.org/package $=$ metafor

Welcome SE, Chiarello C, Towler S, Halderman LK, Otto R, Leonard CM (2009) Behavioral correlates of corpus callosum size: anatomical/behavioral relationships vary across sex/handedness groups. Neuropsychologia 47(12):2427-2435. https://doi.org/10. 1016/j.neuropsychologia.2009.04.008

Westerhausen R, Walter C, Kreuder F, Wittling RA, Schweiger E, Wittling W (2003) The influence of handedness and gender on the microstructure of the human corpus callosum: a diffusion-tensor magnetic resonance imaging study. Neurosci Lett 351(2):99-102

*Westerhausen R, Kreuder F, Dos Santos Sequeira SD, Walter C, Woerner W, Wittling RA et al (2004) Effects of handedness and gender on macro- and microstructure of the corpus callosum and its subregions: a combined high-resolution and diffusion-tensor MRI study. Cogn Brain Res 21(3):418-426. https://doi.org/10. 1016/j.cogbrainres.2004.07.002

Westerhausen R, Kreuder F, Sequeira SDS, Walter C, Woerner W, Wittling RA et al (2006) The association of macro-and microstructure of the corpus callosum and language lateralisation. Brain Lang 97(1):80-90

*Witelson SF (1985) The brain connection: the corpus callosum is larger in left-handers. Science 229(4714):665-668. https://doi.org/ 10.1126/science. 4023705

*Witelson SF (1989) Hand and sex differences in the isthmus and genu of the human corpus callosum. A postmortem morphological study. Brain 112(Pt 3):799-835. https://doi.org/10.1093/brain/ 112.3.799

*Witelson SF, Goldsmith CH (1991) The relationship of hand preference to anatomy of the corpus callosum in men. Brain Res 545(12):175-182. https://doi.org/10.1016/0006-8993(91)91284-8

Witelson SF, Nowakowski RS (1991) Left out axons make men right: a hypothesis for the origin of handedness and functional asymmetry. Neuropsychologia 29(4):327-333

Yoshii F, Duara R (1989) Size of the corpus callosum in normal subjects and patients with Alzheimer's disease-magnetic resonance imaging study. Rinsho Shinkeigaku Clin Neurol 29(1):1-7

Zapała D, Zabielska-Mendyk E, Augustynowicz P, Cudo A, Jaśkiewicz M, Szewczyk M et al (2020) The effects of handedness on sensorimotor rhythm desynchronization and motor-imagery BCI control. Sci Rep 10(1):1-11

Publisher's Note Springer Nature remains neutral with regard to jurisdictional claims in published maps and institutional affiliations. 